\title{
CHRONIC GENITAL ULCER DISEASE WITH SUBSEQUENT DEVELOPMENT OF METHICILLIN-RESISTANT STAPHYLOCOCCUS AUREUS (MRSA) URETHRITIS AND BACTERAEMIA IN AN HIV-SEROPOSITIVE PERSON - A CASE OBSERVATION
}

\author{
Christine Katusiime, $M B C h B, P G D P P M, M I P H$ \\ Andrew Kambugu, $M B C h B, M M e d$ \\ Infectious Diseases Institute, College of Health Sciences, Makerere University, Kampala, Uganda
}

\begin{abstract}
HIV-seropositive persons are at increased risk of methicillin-resistant Staphylococcus aureus (MRSA). Genital ulcerative disease and sexually transmitted infection with subsequent MRSA infection in HIV-seropositive persons have been documented only once. We report a case of a 44-year-old man who presented to the Infectious Diseases Institute, Kampala, Uganda, with chronic genital ulcer disease and who subsequently developed MRSA urethritis and bacteraemia. This case also demonstrates that persistent genital ulcer disease in HIV-seropositive persons may be as a result of concurrent MRSA infection.
\end{abstract}

HIV-seronegative persons are less likely to become infected with Staphylococcus aureus and associated S. aureus septicaemia than their HIV-seropositive counterparts. ${ }^{1,2}$ Studies have demonstrated an increased risk of MRSA infection among HIVseropositive persons of up to 18 times. ${ }^{3-5}$ MRSA infection therefore presents a public health concern. MRSA infection has also been found to be associated with sexually transmitted infections (STIS) and genital ulcer disease (GUD) in HIV-seropositive persons. ${ }^{6}$ GUD with associated MRSA infection has only been documented once. ${ }^{6}$ The case we present in this report is of chronic genital ulceration complicated by MRSA urethritis and bacteraemia. This case of chronic GUD with subsequent MRSA infection in an HIV-seropositive host also highlights the importance of ruling out concurrent MRSA infection in chronic GUD in HIV-seropositive persons.

\section{CASE PRESENTATION}

A 44-year-old HIV-seropositive man with World Health Organization (WHO) stage IV disease, who had been on highly active anti-retroviral therapy (HAART) of tenofovir, lamivudine and efavirenz, and co-trimoxazole prophylaxis since March 2008, presented with an 8-month history of genital ulceration and a 4-month history of urethral pus discharge. He initially noticed a small papule on the glans of his penis which increased in size and ulcerated. He subsequently developed a yellow non-odorous urethral discharge. On review of symptoms, he denied associated fevers and chills, or trauma to the site. He had no significant previous medical history and denied cigarette smoking, alcohol consumption and intravenous drug usage. He was heterosexual, denied unsafe sexual practices, and had no history of previous STIs, antibiotic use, and recurrent STIs or GUD.

Physical examination revealed a body temperature of $36.1^{\circ} \mathrm{C}$, pulse rate 86 beats per minute, blood pressure $120 / 70 \mathrm{mmHg}$, and respiratory rate 12 breaths per minute. Genital examination revealed an ulcer involving the glans of the penis with a yellow urethral discharge. Precordial, ophthalmic, gastrointestinal and respiratory examinations were unremarkable. Neurologically, there were no cranial nerve deficits, reflexes were symmetrical and normal, and distal sensation was intact.

Laboratory data revealed a white blood cell (WBC) count of $5000 / \mathrm{mm}^{3}$ and an elevated erythrocyte sedimentation rate (ESR) of $80 \mathrm{~mm} / \mathrm{hr}$. His urine revealed 500 leukocytes/ul, trace protein, 66 white blood cells/high-power field (hpf) and 1 cast/hpf. The rest of the routine laboratory tests including renal function tests, liver function tests, random blood sugar (RBS), Treponemal pallidum haemagglutination assay (TPHA), serum cryptococcal antigen (CRAG) titres, hepatitis $B$ surface antigen $(\mathrm{HBsAg})$ and brucella agglutination assay were unremarkable. CD4+ cell counts were 944 cells $/ \mathrm{mm}^{3}(30 \%)$, and plasma HIV RNA levels were undetectable. Herpes simplex virus-2 (HSV-2) serology could not be done because of the high costs involved.

A penile wedge biopsy taken for histopathological examination showed features suggestive of a chronic penile ulcer. The urethral pus swabs and blood cultures grew MRSA sensitive to gentamicin, ciprofloxacin and vancomycin but resistant to oxacillin, tetracycline, penicillin and erythromycin. Urine cultures depicted no growth. A clinical diagnosis of chronic ulcerative genital herpes was made, following consultation with an STD specialist. The patient was then admitted and commenced on a course of oral acyclovir $400 \mathrm{mg}$ twice daily for 6 months and intravenous vancomycin for 2 weeks for chronic ulcerative genital herpes and MRSA urethritis and bacteraemia respectively. Intravenous ceftriaxone was also administered to treat the urinary tract infection (UTI). Continual adherence to co-trimoxazole, acyclovir and HAART was continually emphasised. 


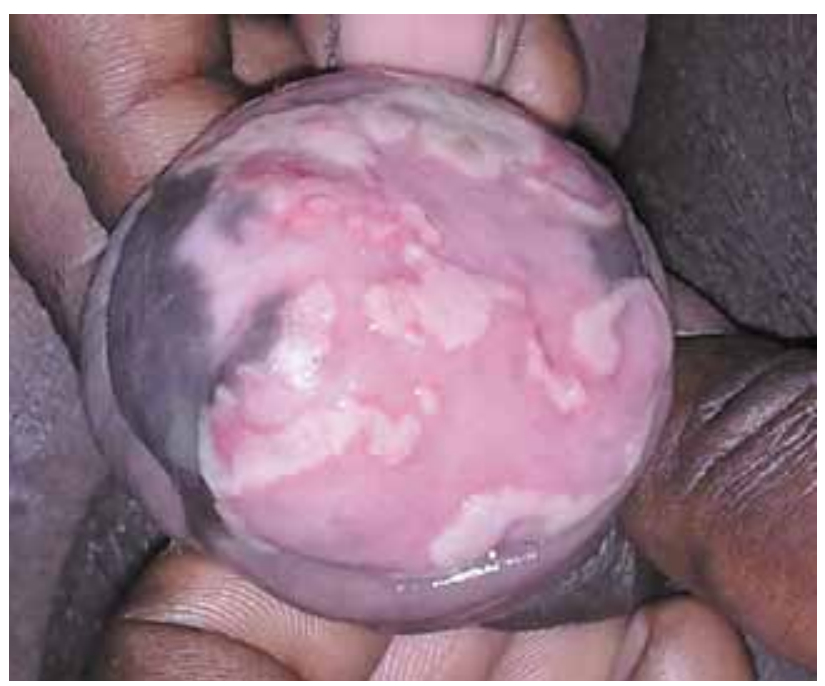

Fig. 1. Ulceration and yellow penile urethral discharge.

The course of treatment was successful; examination at 1 month and 2 months follow-up revealed no urethral discharge and completely healed penile ulcerations.

\section{DISCUSSION}

HIV-infected persons have a higher risk of MRSA infection than the general population. ${ }^{3-9}$ The reason why our patient was predisposed to MRSA infection could have been a result of the chronic genital ulceration.

Prior studies have implicated lack of co-trimoxazole prophylaxis, intravenous drug usage, low CD4 T-cell count, high HIV viral load and hospitalisation as risk factors for MRSA colonisation in HIVseropositive patients. ${ }^{10-12}$ These factors, however, were not noted in our patient. Ramsetty and colleagues demonstrated that HIVseropositive patients with CD4 T-cell counts $<200$ cells $/ \mathrm{mm}^{3}$ were at significant risk of MRSA infections. ${ }^{13}$ Our patient was the exception to this finding, as his CD4 T-cell count was 944 cells/ $\mathrm{mm}^{3}$.

A ramification of this case is the importance of considering concurrent MRSA infection in HIV-seropositive patients with chronic GUD. Other factors that make this case unique are the development of MRSA urethritis and bacteraemia despite the patient's high CD4 T-cell counts and good virological control.

\section{CONCLUSION}

Our patient developed MRSA infection following chronic GUD that was not effectively managed. Clinicians need to maintain vigilance in the

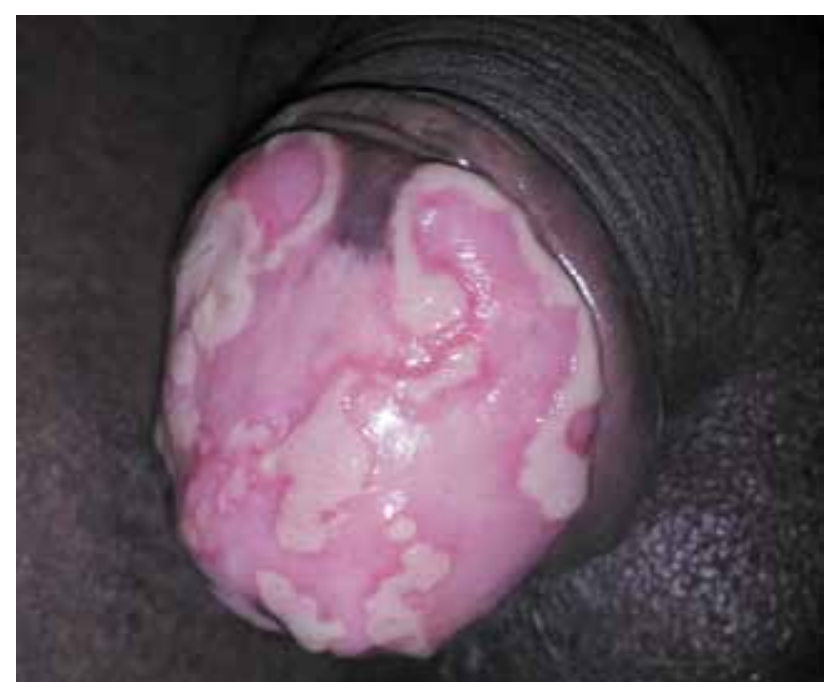

Fig. 2. Ulceration involving entire glans.

management of chronic GUD in HIV-seropositive persons, as MRSA coinfection may become an increasing complication in the future.

\section{REFERENCES}

1. Enthilkumar A, Kumar S, Sheagren J. Increased incidence of Staphylococcus aureus bacteremia in hospitalized patients with acquired immunodeficiency syndrome. Clin Infect Dis 2001:33:1412-1416.

2. Weinke T, Schiller R, Fehrenbach FJ, Pohle HD. Association between Staphylococcus aureus nasopharyngeal colonization and septicemia in patients infected with the human immunodeficiency virus. Eur J Clin Microbiol Infect Dis 1992;11:985-989.

3. Matthews WC, Caperna JC, Barbaer RE, et al. Incidence of and risk factors for clinically significant methicillin-resistant Staphylococcus aureus infection in a cohort of HIV infected adults. J Acquir Immune Defic Syndr 2005;40:155-160.

4. Crum-Cianflone NF, Burgi AA, Hale BR. Increasing rates of community-acquired methicillin-resistant Staphylococcus aureus infections among HIV-infected persons. Int J STD AIDS 2007;18:521-526.

5. Popovich KJ, Weinstein RA, Aroutcheva A, Rice T, Hota B. Community-associated methicillin-resistant Staphylococcus aureus and HIV: Intersecting Epidemics. Clin Infect Dis 2010;50:979-987.

6. Crum-Cianflone NF, Shadyab AH, Weintrob A, et al. Association of methicillin-resistant Staphylococcus aureus (MRSA) colonization with high-risk sexual behaviors in persons infected with human immunodeficiency virus (HIV). Med 2011;90:379-389.

7. Burkey MD, Wilson LE, Moore RD, Lucas GM, Francis J, Gebo KA. The incidence of and risk factors for MRSA bacteraemia in an HIV-infected cohort in the HAART era. HIV Med 2008;9:858-862.

8. Cenizal MJ, Hardy RD, Anderson M, Katz K, Skiest DJ. Prevalence of and risk factors for methicillinresistant Staphylococcus aureus (MRSA) nasal colonization in HIV-infected ambulatory patients. Acquir Immune Syndr 2008:48:567-571.

9. Diep BA, Chambers HF, Graber $\mathrm{C}$, et al. Emergence of multidrug-resistant community-associated methicillin-resistant Staphylococcus aureus clone USA300 in men who have sex with men. Ann Intern Med 2008;148:249-257.

10. Sissolak D, Geusau A, Heinze G, Witte W, Rotter ML. Risk factors for nasal carriage of Staphylococcus aureus in infectious disease patients, including patients infected with HIV, and molecular typing of colonizing strains. Eur J Clin Microbiol Infect Dis 2002;21:88-96.

11. Szumowski JD, Wener KM, Gold HS, et al. Methicillin-resistant Staphylococcus aureus colonization, behavioral risk factors, and skin and soft-tissue infection at an ambulatory clinic serving a large population of HIV-infected men who have sex with men. Clin Infect Dis 2009:49:118-121.

12. Villacian JS, Barkham T, Earnest A, Paton NI. Prevalence of and risk factors for nasal colonization with Staphylococcus aureus among human immunodeficiency virus-positive outpatients in Singapore. Infect Control Hosp Epidemiol 2004;25:438-440.

13. Shet A, Mathema B, Mediavilla JR, et al. Colonization and subsequent skin and soft tissue infection due to methicillin-resistant Staphylococcus aureus in a cohort of otherwise healthy adults infected with HIV type 1. J Infect Dis 2009;200:88-93.

14. Ramsetty SK, Stuart LL, Blake RT, Parsons CH, Salgado CD. Risks for methicillin-resistant Staphylococcus aureus colonization or infection among patients with HIV infection. HIV Med 2010;11:389-394. 